\title{
¿Es necesario modificar el Decreto Legislativo 1071? Comentario al Proyecto de Ley No 1088-2016-CR
}

Rafael Artieda Aramburú

Abogado por la Pontificia Universidad Católica del Perú. Máster en Derecho de la Propiedad Intelectual y de la Competencia de la Pontificia Universidad Católica del Perú. Profesor de la Facultad de Derecho de la Universidad de Lima.

\section{SUMARI0:}

I. Breve comentario sobre el Decreto Legislativo 1071.

II. Análisis del Proyecto de Ley № 1088-2016-CR.

III. Conclusión. 


\title{
RESUMEN:
}

A lo largo del presente artículo, se discutirán las modificaciones propuestas por el Proyecto de Ley № 1088-2016-CR. Asimismo, el autor, presentará una serie de críticas que sustentan su conclusión de por qué considera que dicho Proyecto de Ley contraviene los principios y estándares internacionales que sustentan la Ley General de Arbitraje, y cómo podría incluso afectar el correcto funcionamiento de la institución en nuestro país.

Palabras Clave: Arbitraje, Proyecto de Ley, Modificación Normativa.

\begin{abstract}
:
The modifications proposed by the Draft Legislation $N^{\circ} 1088-2016-C R$ will be discussed throughout the following article. Furthermore, the author present a series of arguments that support his conclusion as to why he considers that said Draft Legislation contravenes the international principles and standards that underlie the General Arbitration Law, and how it could even affect the proper functioning of said institution in our country.

Keywords: Arbitration, Draft Legislation, Regulation Reform.
\end{abstract}

\section{BREVE COMENTARIO SOBRE EL DECRETO LEGISLATIVO 1071}

Por Resolución Ministerial № 027-2006-JUS de fecha 25 de enero de 2006, se creó la Comisión Técnica para la revisión de la Ley 26572 —en adelante, "Ley General de Arbitraje"-, con la finalidad, expresada en la Exposición de Motivos del Decreto Legislativo 1071, de:

"(...) ajustar aspectos centrales de la estructura arbitral para tratar de cerrar vacíos y errores que favorezcan un desarrollo eficiente del arbitraje y comprometer a los operadores del sistema a un mayor estudio y una aplicación responsable de la ley, teniendo en cuenta que se trata de un medio para resolver el conflicto y no de un obstáculo".

Como resultado de su trabajo, la Comisión Técnica elaboró un Proyecto Modificatorio de la entonces vigente Ley General de Arbitraje, que tuvo por objeto "(...) presentar un paquete de reformas urgentes que resultan de una evaluación de los problemas centrales identificados".

Entre los elementos o principios que inspiraron las reformas contenidas en el Proyecto Modificatorio se encuentra el de:

"Ajustar la Ley a los últimos avances en la experiencia internacional, y a los estándares comúnmente aceptados, haciendo que las características de nuestra ley sean reconocibles y comprensibles para los inversionistas y comerciantes no solo nacionales, sino extranjeros. En ese sentido se ha buscado usar la Ley de Arbitraje Modelo de UNCITRAL como un referente importante.

\section{(...)}

En ese orden de ideas, los cambios que se proponen en la nueva ley están dirigidos a aumentar la competitividad del Perú como sede de arbitrajes, de manera que pueda ser elegido en la región como lugar adecuado para arbitrar en razón de la existencia de un marco legal seguro y predecible, ajustado a estándares internacionales.

\section{(...)}

Se espera también, de otro lado, que estas nuevas reglas de juego consoliden y afiancen una cultura arbitral en los operadores del sistema, abogados, árbitros, instituciones arbitrales y jueces, por cuanto una sincronización adecuada de estos operadores garantiza un desarrollo óptimo de la institución".

Mediante Ley 29157, publicada en el diario oficial El Peruano el 20 de diciembre de 2007, el Congreso de la República delegó en el Poder Ejecutivo la facultad de legislar, por un plazo de ciento ochenta — 180 — días calendario, sobre 
diversas materias relacionadas con la implementación del Acuerdo de Promoción Comercial Perú - Estados Unidos. La facultad delegada comprendía, entre otras, las siguientes materias:

a) Facilitación del comercio.

b) Mejora del marco regulatorio, fortalecimiento institucional y simplificación administrativa, y modernización del Estado.

c) Mejora de la administración de justicia en materia comercial y contencioso-administrativa.

d) Promoción de la inversión privada.

En el marco de la mencionada delegación de facultades legislativas, y sobre la base del Proyecto Modificatorio elaborado por la Comisión Técnica, con fecha 28 de junio de 2008 fue publicado en el diario oficial El Peruano el Decreto Legislativo 1071, Decreto Legislativo que norma el Arbitraje, que entró en vigencia el $1^{\circ}$ de septiembre de 2008.

Comentando dicha norma, Carlos A. Soto Coaguila y Alfredo Bullard González indican que:

"La reforma se dio en un contexto de promoción de las inversiones y con la finalidad de crear una atmósfera más favorable a los inversionistas y empresas que deseen hacer negocios en el Perú, pues efectivamente se dio en el marco de la implementación del TLC con los Estados Unidos".

Los mismos autores señalan que:

"(...) la nueva norma tiene principalmente dos objetivos. En primer lugar, mantener los éxitos alcanzados en el arbitraje doméstico $y$, en segundo lugar, extender dichos éxitos al arbitraje internacional posicionando al Perú como sede de dichos arbitrajes"' .

Por su parte, el profesor español Fernando Mantilla-Serrano comenta lo siguiente:

"La nueva ley peruana de arbitraje de 2008 en adelante, la "Ley de Arbitraje" o "la nueva ley" - constituye, junto con la ley de la República Dominicana del mismo año y la reciente reforma en Costa Rica, uno de los esfuerzos de actualización legislativa más recientes en América Latina en el área de arbitraje. A partir de esta reforma, Perú logró completar el trabajo de modernización iniciado con la Ley General de Arbitraje de 1996 — en adelante, la "LGA" - cuya redacción, al menos respecto del arbitraje internacional, se inspiraba ya en la Ley Modelo de la CNUDMI sobre Arbitraje Comercial Internacional de 1985"2.

Como puede apreciarse, las normas contenidas en el Decreto Legislativo 1071 son el resultado de un esfuerzo, hasta el momento exitoso, de contar con una legislación de avanzada, que permita profundizar el importante desarrollo que ha tenido el arbitraje doméstico en nuestro país, y consolidarlo como sede arbitrajes internacionales.

En tal sentido, consideramos que cualquier intento de modificar el Decreto Legislativo 1071, como el Proyecto de Ley objeto del presente artículo, debe ser analizado teniendo en cuenta los objetivos antes descritos.

\section{ANÁLISIS DEL PROYECTO DE LEY No 1088-2016-CR}

Con fecha 17 de marzo del año 2017, el Congresista de la República, señor Glider Agustín Ushñahua Huasanga presentó el Proyecto de Ley $N^{\circ}$ 1088-2016-CR, Ley que modifica los artí-

1. Soto COAGUILA, Carlos A. y BULLARD GONZÁLEZ, Alfredo. "Comentarios a la Ley Peruana de Arbitraje". Tomo I. Primera Edición. Instituto Peruano de Arbitraje. Lima, 2011. p. XVIII y ss.

2. MANTILLA-SERRANO, Fernando. "Breves comentarios sobre la nueva Ley Peruana de Arbitraje". En: Revista LimaArbitration. N ${ }^{\circ}$ 4. Lima, 2010-2011. p. 37. 
culos $20^{\circ}$ y $22^{\circ}$ numeral 5 e incorpora el numeral 8 al artículo $25^{\circ}$ y la Séptima Disposición Final al Decreto Legislativo 1071, Decreto Legislativo que norma el Arbitraje.

A continuación analizaremos el Proyecto de Ley en cuestión.

Los textos actualmente vigentes de los artículos $20^{\circ}$ y $22^{\circ}$, numeral 5 del Decreto Legislativo 1071 disponen lo siguiente:

"Artículo 20.- Capacidad. Puede ser árbitro la persona natural que se halle en el pleno ejercicio de sus derechos civiles, siempre que no tenga incompatibilidad para actuar como árbitro y no haya recibido condena penal firme por delito doloso. Salvo acuerdo en contrario de las partes, la nacionalidad de una persona no será obstáculo para que actúe como árbitro ${ }^{3}$.

Artículo 22.- Nombramiento de los árbitros.

\section{(...)}

5. Si una parte no cumple con nombrar al árbitro que le corresponde en el plazo establecido por las partes o, en su defecto en este Decreto Legislativo, podrá recurrirse a la institución arbitral o al tercero designado por las partes para estos efectos o, en su defecto, procederse según lo dispuesto por el artículo 23".

En caso de aprobarse el Proyecto de Ley bajo comentario, los nuevos textos de los citados artículos serían los siguientes:

"Artículo 20.- Capacidad.

Puede ser árbitro la persona natural que se halle en el pleno ejercicio de sus derechos civiles, siempre que no tenga incompatibilidad para actuar como árbitro y no haya recibido condena penal firme por delito doloso. Salvo acuerdo en contrario de las partes, la nacionalidad de una persona no será obstáculo para que actúe como árbitro en ningún caso, cuando se trate de arbitraje institucional, será requisito encontrarse adscrito a la nómina de árbitros de la institución arbitral que administrará el arbitraje, para poder desempeñarse como árbitro de parte, árbitro único o presidente de tribunal arbitral; es nula de pleno derecho toda disposición en contrario, incluida las ratificaciones o confirmaciones por la instituciones arbitrales, salvo que tales requisitos sean convenidos de manera expresa por las partes en el respectivo convenio arbitral" (subrayado agregado).

\section{(...)}

Artículo 22.- Nombramiento de los árbitros.

\section{(...)}

5. Si una parte no cumple con nombrar al árbitro que le corresponde en el plazo establecido por las partes o, en su defecto en este Decreto Legislativo, podrá recurrirse a la institución arbitral o al tercero designado por las partes para estos efectos o, en su defecto, procederse según lo dispuesto por el artículo 23. Cuando la designación residual deba ser efectuada por una institución arbitral, ésta efectúa la designación eligiendo objetiva y aleatoriamente al árbitro por defecto entre los árbitros que integren su nómina de árbitros, la misma que deberá ser mostrada inmediatamente en la página web de la institución arbitral, caso por caso. Las nóminas de árbitros servirán únicamente para dar cumplimiento a lo previsto por este inciso, así como cuando se proceda según lo dispuesto en el artículo 23" (subrayado agregado).

Asimismo, el Proyecto de Ley contempla la propuesta de incorporación del numeral 8 al artículo $25^{\circ}$ y de la Séptima Disposición Final al nombramiento de árbitros, así como la incorpo-

3. Modificado por Decreto Legislativo 1231, publicado en el diario oficial El Peruano el 26 de septiembre de 2015. 
ración y separación de árbitros de las instituciones arbitrales, conforme a los textos siguientes:

"Artículo 25.- Nombramiento por las Cámaras de Comercio.

\section{(...)}

8. Los integrantes de los Consejos Superiores o Cortes de Arbitraje o cualquier otra denominación, de las instituciones arbitrales, serán integrados por personas que a título individual o colectivo, no se dediquen al ejercicio de la defensa del proceso arbitral, ya sea como abogados o peritos.

Las Universidades que constituyan Centros de Arbitraje, los integrantes de dichos Consejos superiores o Cortes de Arbitraje, adicionalmente a los impedimentos del párrafo anterior, no podrán estar integrados por profesores de ninguna categoría de la misma universidad.

Los colegios profesionales que constituyan centros de arbitraje, los integrantes de dichos Consejos Superiores o Cortes de Arbitraje, adicionalmente a los impedimentos del párrafo anterior, no podrán estar integrados por directivos de ninguna categoría de dicha institución.

\section{(...)}

"DISPOSICIONES COMPLEMENTARIAS FINALES

(...)

SÉPTIMA.- Incorporación y separación de la nómina de árbitros.

Para ser incorporado a la nómina de árbitros de una institución arbitral, se deberá cumplir los requisitos objetivos que para tal fin establezca cada institución arbitral, los cuales deberán ser de público conocimiento de manera previa a la solicitud de incorporación. Todo requisito establecido por una institución arbitral para la incorporación de árbitros a sus nóminas, que importe una valoración subjetiva o discriminación por cualquier causa, será nula de pleno derecho.

La separación o exclusión de un árbitro adscrito a la nómina de árbitros de una institución arbitral, solo puede efectuarse si existen circunstancias objetivas debidamente comprobadas que ameriten dicha separación. Esta decisión de la institución arbitral deberá estar debidamente motivada y comunicada oportunamente al árbitro excluido, previo ejercicio de su derecho de defensa, permitiéndosele efectuar los descargos que resultaren pertinentes".

En la Exposición de Motivos del Proyecto de Ley en cuestión, se indica como justificación de las modificaciones propuestas, que en los arbitrajes institucionales, los centros de arbitraje estarían imponiendo como requisito, para el ejercicio de la función arbitral en los procesos arbitrales administrados por dichas instituciones, además de los establecidos en la Ley, el de encontrarse adscrito a la nómina de árbitros del centro de arbitraje de que se trate.

A criterio del autor del Proyecto de Ley, se trataría de un requisito "subjetivo", que "(...) colisiona directamente con la ley que no realiza ningún distingo y con la constitución porque pone barreras subjetivas a quienes pretenden integrar dichos centros de arbitraje, lo que constituye una discriminación de los derechos humanos".

Por nuestra parte, discrepamos con la modificación propuesta por el Proyecto de Ley, y con la justificación expuesta en su Exposición de Motivos.

En efecto, el artículo $6^{\circ}$ del Decreto Legislativo 1071 contempla, entre las reglas de interpretación aplicables, las siguientes:

"Artículo 6.- Reglas de interpretación. Cuando una disposición de este Decreto Legislativo:

a. Deje a las partes la facultad de decidir libremente sobre un asunto, esa facultad comprenderá la de autorizar a un tercero, incluida una institución arbitral, a que adopte esa decisión.

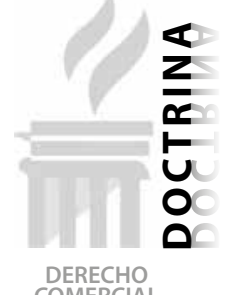

COMERCIAL

.


b. Se refiera al convenio arbitral o a cualquier otro acuerdo entre las partes, se entenderá que integran su contenido las disposiciones del reglamento de arbitraje al que las partes se hayan sometido".

Tal como se indica en la Exposición de Motivos de la Ley de Arbitraje actualmente vigente, uno de los elementos o principios que inspiraron dicha norma es:

"a. Reforzar el carácter autónomo del arbitraje, tanto de la jurisdicción ordinaria, como de las reglas procesales comunes, reconociéndolo como una institución que tiene sus propios principios y reglas. Para ello se ha reforzado la defensa de la competencia de los árbitros, priorizando un control ex post de las actuaciones arbitrales, por medio del recurso de anulación, y evitando el uso de recursos o intervenciones ex ante al dictado del laudo arbitral".

Comentando las reglas de interpretación contenidas en el artículo $6^{\circ}$ de la Ley de Arbitraje y su Exposición de Motivos, el doctor Felipe Osterling Parodi señalaba que:

"(...) como parte de dicha búsqueda de autonomía y de una mejor regulación que evite interferencias que afecten la continuidad del proceso arbitral, las reglas de interpretación de la Ley de Arbitraje constituyen una de las modificaciones que trae la nueva ley y que responden al objetivo de armonizar el lenguaje a partir de estándares internacionales"'.

Asimismo, en la Exposición de Motivos de la Ley de Arbitraje española ${ }^{5}$, cuyo artículo $4^{\circ}$ contiene reglas de interpretación muy similares a las del artículo $6^{\circ}$ de la Ley de Arbitraje peruana, se indica, acertadamente en nuestra opinión, lo siguiente:

"El artículo 4 contiene una serie de reglas de interpretación, entre las que tienen especial relevancia las que dotan de contenido a las normas legales dispositivas de esta ley mediante la remisión, por voluntad de las partes, a la de una institución arbitral o al contenido de un reglamento arbitral. Así, esta ley parte en la mayoría de sus reglas de que debe primar la autonomía de la voluntad de las partes. Mas esa voluntad se entiende integrada por las decisiones que pueda adoptar, en su caso, la institución administradora del arbitraje, en virtud de sus normas, o las que puedan adoptar los árbitros, en virtud del reglamento arbitral al que las partes se hayan sometido. Se produce, por tanto, una suerte de integración del contenido del contrato de arbitraje o convenio arbitral, que, por mor de esta disposición, pasa a ser en tales casos un contrato normativo. De este modo, la autonomía privada en materia de arbitraje se puede manifestar tanto directamente, a través de declaraciones de voluntad de las partes, como indirectamente, mediante la declaración de voluntad de que el arbitraje sea administrado por una institución arbitral o se rija por un reglamento arbitral. En este sentido, la expresión institución arbitral hace referencia a cualquier entidad, centro $u$ organización de las características previstas que tenga un reglamento de arbitraje y, conforme a él, se dedique a la administración de arbitrajes. Pero se precisa que las partes pueden someterse a un concreto reglamento sin encomendar la administración del arbitraje a una institución, en cuyo caso el reglamento arbitral también integra la voluntad de las partes".

Siguiendo el razonamiento indicado, que es consistente con los estándares internacionales que informan y dan contenido al Decreto Legislativo 1071, tenemos que los textos actualmente vigentes de sus artículos $20^{\circ}$ y $22^{\circ}$, numeral 5 no contienen un requisito ilegal y discriminatorio para el ejercicio de la función arbitral, como equivocadamente se afirma en la Exposición de Motivos del Proyecto de Ley, sino que, siendo consistentes con las reglas de interpretación contenidas en el artículo $6^{\circ}$ del Decreto Legis-

5. Ley 60/2003, de 23 de diciembre de 2003. 
lativo 1071, según las cuales las partes, en ejercicio de su autonomía, perfectamente pueden someter determinados aspectos del arbitraje, tales como su administración, los reglamentos arbitrales, entre otros, a una institución arbitral.

En tal sentido, carece de sentido imponer legalmente limitaciones a las decisiones de las instituciones arbitrales a cuyas reglas y/o administración las partes, en ejercicio de su autonomía, han decidido voluntariamente someterse.

Tampoco sería conveniente, a nuestro criterio, que la Ley de Arbitraje incorpore normas que intervengan en los procedimientos internos y reglas que debe establecer cada institución arbitral para la designación de los integrantes de sus órganos internos, o para la designación y/o exclusión de los profesionales que integran su nómina de árbitros, ya que ello implicaría una indebida interferencia estatal en aspectos organizativos que, conforme a los principios generales que informan a la vigente Ley de Arbitraje y, en general, a nuestro ordenamiento jurídico, pertenece al ámbito de la autonomía privada de cada institución arbitral, que debe preservase, a fin de no afectar la esencia de la institución arbitral.

\section{CONCLUSIÓN}

Por las razones expuestas en el presente artículo, consideramos que la eventual promulgación del Proyecto de Ley bajo comentario sería contraria a los principios y estándares internacionales que sustentan al Decreto Legislativo 1071 y a la institución del arbitraje, y susceptible de afectar el correcto funcionamiento del arbitraje en nuestro país. 